\title{
Contact North: linking community learners and educational institutions
}

Terry Anderson is Director of the North West Region of Contact North/Contact Nord, a delivery network for distance education for northern and often remote communities in Ontario, Canada. In this article he argues that Student Support Services dispersed in the community are better able to meet student needs than those which remain based in the institution. He also seeks to demonstrate that a network with only delivery functions can effectively help students meet their needs from a range of course providers.

\section{Terry Anderson}

$\mathrm{T}$ he human, capital and operational resources required to provide quality, distance education delivery and support services in many communities spread over large distance is often beyond the resources of any single education deliverer. As a response to these high costs, a number of multi purpose delivery networks have been established in Canada (Alberta Teleconferencing Network, Contact North, Open Learning Agency - British Columbia, Saskatchewan Communications and Access Network).

The functions and services of these delivery networks vary in scope, mandate and capacity. Some have mandates that include the development of course material and granting of degrees on their behalf. Others are limited to the delivery and distribution of courseware from other accredited educational institutions. Generally, these delivery networks provide information services to enrolled and prospective learners, learning centres for interactive distance delivery of courses, technical troubleshooting and instruction in use of delivery technologies and informal, first line student support and referral services.

These delivery networks are filling a service and development role both for the institutions and the learners. In addition they serve as a bridge between urban based institutions and the community based learners.

This paper briefly outlines the objectives, technical configuration, staffing, governance and the major usage of the Contact North distance education delivery network. It then discusses the services that the project provides to education delivery institutions and to community based learners.
The perspective of the paper views the evolution of these new networks from a 'neutral highway' orientation to one of active partners, assisting in educational and personal development by both learners as individuals and collectively as communities.

Traditionally, student support functions have been housed within the educational institution. ' This physical separation between learners and delivery support services tends to decrease the access and subsequent use of student support services by distance learners. For example Burge et $\mathrm{al}^{2}$ found that over 50 per cent of students enrolled in distance education courses made no use of off campus library services. Discussions with counselling staff at Lakehead University have revealed that few students take advantage of the study skills, personal or peer counselling services that have been developed to assist distance learners. In contrast, Contact North works actively in 32 small northern communities. Part time staff, known as site coordinators, provide a range of student support services in the local community. The site coordinator is very visible, has frequent contact with learners and can identify the community learning context within which he or she must operate. $^{3}$

The student support activities of the site coordinator are undertaken within the operating principles and practices of both the Contact North system and the educational institutions (e.g. colleges and universities). To date, these institutions have been guided by a delivery model best characterised as one that views education as a commodity to be dispensed. In Boot and Hodgsons' ${ }^{\prime 4}$ terms, this dissemination model misconstrues the nature of learning and neglects the development needs of students. In contrast, an adequate developmental model 
would recognise the personal situation of learners and 'support their efforts in creating and validating their own meanings'. To take advantage of the opportunities made available through programmes developed and delivered with a developmental orientation, students must become directly engaged in the delivery process itself. The current issue within Contact North and other distributed educational networks is the manner in which this involvement will be undertaken. However the process evolves, it is increasingly apparent that the planning and development must take place within the communities as well as the educational delivery institutions. In particular the role of the local site co-ordinator will be central to achieving a more responsive delivery system.

\section{Overview - Contact North Contact Nord}

Contact North is a project of the Ontario government, designed to increase access to formal and informal educational programming to the residents of Northern Ontario. The majority of Canadians live in the southern part of the country, for the most part in large cities distributed along the border with the U.S.; however, a significant number reside in relatively small, isolated communities in the North. Some sense of the geographic distances and population densities involved in the area served by the Contact North Project may be gained from a comparison: in Northern Ontario, approximately 800,000 people are spread over an area of 780,000 sq. kilometres. This is less than 2 per cent of the population of the United Kingdom, distributed over three times the land mass.

The objectives of the four year, 20 million dollar project are discussed in Roberts et al. ${ }^{5}$ In brief, Contact North was set up as a delivery network, which uses interactive telecommunications technologies to deliver distance education programming. In addition the project established learning centres that provide a variety of student services in the remote communities.

The governance of the project is complicated with several government departments, delivery institutions and community representatives having input into policy making, governance and operations of the project. The governance structure was designed to ensure ownership and participation by the key stake holders and has built in mechanisms that demand collaboration between the major stake holders in most management areas. On occasion this enforced collaboration has worked at the expense of efficiency, yet the collaboration has also fostered the development of a wide cross section of institutional, government and community support.

Contact North was established as a change agent with a mandate to innovate and create 'new and expanding expertise' and to function as a 'test-bed' for technologies in delivering distance education.

Kimberly ${ }^{6}$ discusses organisational and contextual influences on the diffusion of technological change. He develops a taxonomy that attempts to classify organisation and innovation. Using this taxonomy, Contact North is a Type V. Organisation - The Organisation as Innovation. In this category a new organisation is created to solve a particular problem. A new organisation offers enhanced opportunity for innovation, especially amongst systems not known for innovative capacities such as established educational institutions. With its mandate to develop new markets, serving all delivery institutions at both post secondary levels, it was important to create a new organisation. The new organisation would not be identified with any one existing institution or agency (both by the general public and the delivering institutions) and thus was free to develop its own distinct identity.

In order to accommodate the widest variety of delivery modes currently in use to distance education delivery institutions in Ontario, Contact North has configured its network with a heterogeneous collection of educational delivery technologies. A 40 port digital teleconferencing bridge as well as the CoSy computer conferencing system was purchased for each of the two regional co-ordinating centres. In addition each of 32 community access sites is equipped with a teleconferencing convener, a facsimile machine, a video tape playback system and television, an IBM AT and a Unisys ICON microcomputer as well as an audio cassette recorder and telephone answering system. Telewriter II audiographic devices are also used at each site to enhance the teleconferencing capacity on the network.

An unplanned for consequence of the animation roles of professional staff working in the native and francophone communities, was 
the demand for delivery services in over 70 additional small communities that were not targeted nor funded for development as access sites'. This demand led to innovations in equipment procurement (purchases by community organisations, schools and other government agencies besides Contact North) and in student support (use of volunteers, schools and community workers as well as short term funding for part time staff by Contact North). The innovative governance and organisational adaptiveness of the organisation provided the flexibility to respond to these unplanned requests for service.

To date the major users of the Contact North network have been northern colleges, universities and secondary schools delivering credit programming (see Figure 1). The network is also used by non-profit community organisations (Boy Scouts, Literacy Groups) and professional groups (Law Society of Upper Canada, Canadian Association for Distance Education) for meetings and training activities.

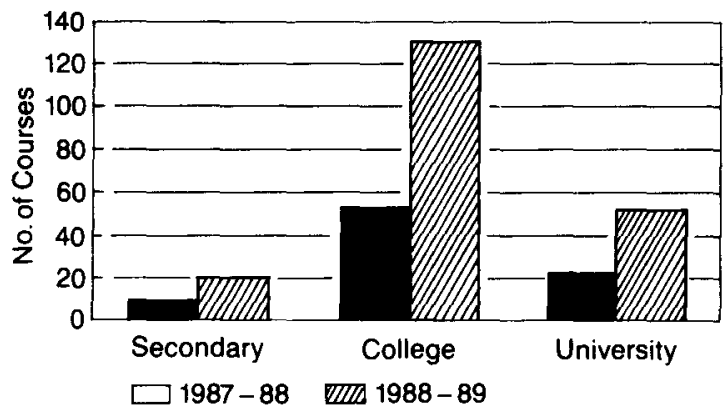

Figure 1 Audio Teleconferenced Courses Contact North Network

In the various Northern access site communities, the Contact North facility consists of a small multi-purpose classroom(s) available as a study and information centre as well as reception points for teleconferenced programme delivery. The access points are located in a variety of sites including college extension offices, public schools, community training centres and other available locations. The communities are required to provide a rent free site facility as their contribution to the project. Various community groups and local education institutions must then develop collaborative arrangements to share the local Contact North resources.

The most common mode of delivery currently being used on the Contact North network is print and audio or video tape packages supplemented by audio teleconferencing. The number of registered students in teleconference supported courses has doubled in each of the three years of the project and is expected to be over 6,000 in the 1989-90 academic year. The facsimile machines are being used for rapid turnaround of student assignments and tests.

\section{Services within educational institutions}

\section{Staff training and professional development}

None of the secondary and less than half the post secondary education institutions in the region offered any distance education programming prior to the establishment of the Contact North project. Thus a major task for Contact North was to act as change agents, assisting institutions and faculties to develop distance education programming, infrastructure and delivery strategies. To assist in this task developmental staff were hired in each regional co-ordinating centre. These staff included instructional design officers, Secondary School liaison officers and liaison officers working with two special target groups: francophone and native learners.

Development staff organise ongoing training and professional development inservices as well as sessions introducing distance education technologies and programming in local communities. These sessions are gradually moving from face-to-face to 'at a distance' seminars as technologies become more widely available and staff have time to develop teleconference and packaged training materials.

\section{Northern Distance Education Fund}

A key ingredient ensuring post secondary participation in the project was the allocation of 40 per cent ( $\$ 8$ million) of Contact North project funds to a new Northern Distance Education Fund (NDEF). The fund was used to develop or purchase distance education programming. The conditions of application to the fund include the following:

- priority given to projects undertaken in a collaborative manner

- full programmes, not courses to be developed

- content and delivery methodology to meet clearly northern needs 
- development of new programmes not currently available in Ontario

- encourage quality development by the use of a course team approach

A total of 22 projects were approved for feasibility studies and 15 full degree or certificate programmes have been approved for funding under the programme. (See Contact North 1988 Annual Report for listing of these programmes). The absence of a similar fund for secondary programme development has resulted in significantly less programming at the secondary level (see Figure 1). A peer review of materials developed through this fund ${ }^{7}$ concluded that the packages were 'quality Canadian distance learning materials, but that there was a need for more consideration of the design and production of the audio and video components of distance education courses. In particular, these two components need to become more integral parts of the course design and delivery'.

A major problem when designing interactive components into a course package is the lack of access to the technologies by all potential students. There was a constant tendency to increase access potential of the courses by decreasing use of the interactive technologies. The print based correspondence course, as lowest common denominator became the defining feature of many courses. This was ironical in that the project that funded course development had the mandate to test-bed various technologies in delivering distance education. Although the majority of courses attempted to build in optimal audioteleconferencing components, little course development went into developing resources (including TeleWriter slides) or instructional aids for teachers expected to use this technology.

\section{Feedback to delivery institutions}

Contact North staff are constantly meeting and talking to individuals and organisations with diverse educational needs. Many of these needs could be met through distance education. Contact North contacts with course developers and deliverers at all levels of formal education allow these needs and requests to be focused on the institution most likely to have or be capable of producing the necessary programming. The fact that Contact North does not develop nor deliver programming on its own behalf, but serves as a delivery vehicle for other institutions, puts the organisation in a unique non-competitive relationship with the individual institutions.

The presence of active distance education proponents in the communities also can be perceived as threatening by distance education delivery institutions. As learner advocates, Contact North staff are quick to notice gaps in services from the institutions, though they are often less quick to appreciate the human and fiscal restraints under which educational institutions operate.

Nelson and Minore ${ }^{8}$ reported that only 27 per cent of the population in North Western Ontario felt that there were opportunities for local residents to influence the ways in which courses are delivered. The same study reported that 91 per cent felt that students should have input into what courses are delivered. They concluded that Northwestern Ontario residents strongly indicate that they want to have a voice in their education options - in deciding the type of courses, the way the courses are delivered, and even course content'. By opening communications channels between institutions and learners Contact North works to enhance the relevance of distance education programming to community learners.

\section{Community based support services}

Experience within the Contact North project has determined that the key to effective community support of distance education is the establishment of community 'access sites' staffed by part time, distance education facilitators referred to as 'site co-ordinators'. Hickling ${ }^{9}$ concluded that the site co-ordinators are an innovative and important element of the application of technology to improve the accessibility of Northerners to educational opportunities'. Student surveys by Hickling determined that over 89 per cent of students using the Contact North programme obtained assistance from the site co-ordinators. This assistance included help with technologies (60 per cent), motivational support (40 per cent) and help with course work (34 per cent). Contact North attempts to increase 'access' to distance education programming through a number of community based services including study centres, information services and advocacy and referral. 


\section{Study Centres}

The Contact North access sites in small northem communities serve as study and learning centres for distance education learners. Tomlinson $^{10}$ describes the necessity of establishing physical facilities to support distance learners. According to Tomlinson the functions of these study centres are threefold.

- a meeting place for students and tutors

- a place to share the use of equipment

- a place to access library materials

The Contact North sites provide meeting facilities and the 'warm coffee pot' for students. However, due to the very large distances involved, most of the interactions between students and tutors take place via audioteleconference. Equipment such as the micro computers and the video machines are used extensively by students. Some of the institutions provide study centres kits with reference books, tapes etc., that act as specialised learning libraries. Access to libraries by distance education students in Northern Ontario is problematic. ${ }^{11}$ Access to online catalogues as well as recent implementation of 24 hour toll free telephone inquiry services at a number of institutions should help to provide this service to northern learners.

A major issue facing Contact North in the future is the availability of suitable space as programming and student numbers increase. The policy that rent free accommodation be provided as a community contribution to the project has strained the capacity of some communities where adequate and secure facilities are in very short supply.

\section{Information services}

Calendars and promotional materials from over 50 educational institutions from across Canada are displayed in the small reference libraries maintained at the access sites. The number of educational institutions delivering distance education programming in Canada is large and increasing each year. Currently there are 31 university, 64 community colleges and 49 private sector institutions offering distance education courses in Canada. ${ }^{12}$

Delivery institutions are encouraged to provide sample packages of study materials for student penusal. The CoSy computer conferencing system is used as a data base and query service whereby part time staff and students can make enquiries of other staff and institutional employees relating to available programming.

\section{Interactive technologies}

Boyd ${ }^{13}$ has noted that 'cost effective distance education minimises the uses of administratively expensive local study centres and personal tutor telecommunications, in order to save money even at the expense of effectiveness'. By providing study centres and audio-teleconferencing services to delivery institutions at no cost Contact North can support the development of more personalised programming and increase the quantity and quality of 'dialogue' component of a course. Kaufman ${ }^{14}$ reviews the literature documenting the importance of dialogue as an essential enhancement to distance education based on course packages and concludes that 'an extremely flexible communication system must be provided to permit dialogue among leamers and teachers'. Besides the audiographic enhanced audio-teleconferencing, Contact North provides computer conferencing and facsimile services to learners and delivery institutions.

Although free access to Computer Mediated Communications was provided by Contact North to delivery institutions, to date it has not been incorporated in distance education delivery. CMC has been used extensively within the project for administration purposes ${ }^{15}$ and has been used to publish an electronic student newspaper. The challenges of integrating $\mathrm{CMC}$ within distance education delivery systems have been documented by many including Mason and Kaye. ${ }^{16}$ The Contact North experience has proven that provision of hardware, funding for communication and programme development costs does not of itself guarantee use and development of technologies that are new or foreign to established education delivery models.

\section{Advocacy and referral}

Contact North's access sites are staffed by local, part time site co-ordinators. The role, training and support of these community based support workers is multi facetted. ${ }^{17}$ In brief, front line educational workers such as the site coordinators are confronted with a variety of student issues and problems ranging from lost text books to deep personal and community problems. The site co-ordinators are trained to be good listeners and to know the resources of their local communities and educational 
institutions that can be focused on these problems. Obviously they do not provide in depth student counselling nor can they speak for the institutions that use the delivery network, yet they can and do provide the necessary encouragement and support to help students to help themselves.

The degree to which part time Contact North site co-ordinators should become involved in vocational, academic or personal counselling has been an issue during the project. In particular academic counselling is a very sensitive issue since only the registrar of a particular institution can speak with authority for that institution. However, that registrar is often a thousand kilometres or more away from the distance education student in the community. Site Co-ordinators have also been tempted to become over involved with the wealth of educational, economic and community development problems that exist in Northern Canada. Contact North has not been given the mandate nor funding to use distance education as a direct vehicle for community change and empowerment, yet it is difficult if not impossible to separate educational from political and economic aspirations and expectations.

\section{Support of distance learning culture}

Hughes ${ }^{18}$ has documented the importance of a 'student learning culture' and contends that value systems, behavioral norms and customs cannot be effectively conveyed merely through course materials'. She goes on to argue that:

'off-campus students need to establish an identity within a university culture which they can in part achieve through group interaction. In the process...they create their own version of the university culture which may or may not approximate either the academic culture or the on-campus undergraduate culture. Central to this process is the role of the intermediary, a leader who acts as a broker between the university and the students and controls the version of received reality'.

While the degree to which Contact North staff 'control' the received reality of learners is questionable, Contact North staff in the local communities assist learners in maximising their interest and input in participating fully in their educational experiences. Examples of this type of 'student animation' would include initial support for the charter of the Distance Education Students of Canada (DESC) as well as support for an electronic student's newspaper focusing on issues relevant to distance learners.

\section{Promotion}

Despite the availability of thousands of distance education programmes, it has been our experience that local community residents are generally not familiar with the opportunities which distance education makes available. Contact North has attempted to promote distance education learning through a variety of promotion strategies including posters, selling of sweatshirts, distribution of promotional placemats in local restaurants, local newspaper and radio ads, publishing of a free promotional 'fax directory', regular distribution of nearly 2,000 copies of our newsletter, publishing of an annual report and regular listings of programming delivered via our audioteleconferencing network. In addition Contact North staff make numerous presentations to community groups, educators and professional and industry associations.

\section{Conclusion}

The past decade has seen tremendous growth in the development of programming and institutional capacity to deliver distance educational programming. Distribution networks such as Contact North are finding that the integration of community based learner support, promotion, feedback and information services are equally important as quality courseware in meeting the life long educational needs of learners. Besides the potential for cost effective delivery, the unique capacity of delivery networks to work closely and non competitively with both delivery institutions and community based learners and organisations offers distinct benefits to all those interested in the development of quality distance education alternatives.

\section{References}

${ }^{\mathrm{I}}$ McInnis-Rankin, E. and Brindley, J. (1986) 'Student Support Services' in Mugridge, I. and Kaufman, D. (eds) Distance Education in Canada.

${ }^{2}$ Burge, E., Snow, J., Howard, J. Developing partnerships: An Investigation of Library-Based Relationships with Students and Educators Participating in Distance Education in Northern Ontario. Ontario Institute for Studies in Education. 
${ }^{3}$ Anderson, T. and Nelson, C. (1989) 'Collaboration in Distance Education: Contact North/Contact Nord' in Sweet, R. (ed) Post Secondary Distance Education in Canada, Athabasca University.

${ }^{4}$ Boot, R. and Hodgson, V. (1987) 'Open Learning: Meaning and Experience' in Beyond Distance Teaching - Towards Open Learning, Hodgson, Mann and Snell (eds).

${ }^{5}$ Roberts, J., Croft, M., Derks, P. (1988) 'Contact North/Contact Nord: A Model for Distance Education Project Administration'. Proceedings of the 14th World Congress, International Council for Distance Education, Oslo, Norway.

${ }^{6}$ Kimberly, J.R. (1987) 'Organizational and Contextual Influences on the Diffusion of Technological Innovation' in New Technology as Organizational Innovation ed. Pennings, J. and Buitendam, A.

${ }^{7}$ Hickling Management Consultants (1989) Evaluation of Contact North/Contact Nord, Ministries of Colleges and Universities, Government of Ontario.

${ }^{8}$ Nelson, C. and Minore, B. (1988) Scanning the Dawn of High Tech Education in the North, Lakehead University, Thunder Bay, Ontario, Canada.

${ }_{9}^{9}$ Hickling Management Consultants (1989) ibid.

10 Tomlinson, R. (1984) Local Media Resource Centres' in Bates, A. (ed) The Role of Technology in Distance Education.
$"$ Burge, E., Snow, J., Howard, J, ibid.

${ }^{12}$ University listings from Canadian University Distance Education Directory 1989. Community Colleges from Community Colleges Offering Open or Distance Education from Association of Canadian Community Colleges (1988) and private sector from Slade and Sweet in Post Secondary Distance Education in Canada (1989).

${ }^{13}$ Boyd, G. (1989) 'Contradictory Directions for Distance Education' in Sweet, R. (ed) Post Secondary Distance Education in Canada.

${ }^{14}$ Kaufman, D. (1989) "Third Generation Course Design in Distance Education' Post Secondary Distance Education in Canada, ed R. Sweet, Athabasca University.

is Anderson, T. and Sweet, R. (1990) 'The Use of Computer Mediated Communications as an Administrative Tool and Support system for Collaborative Work'. Proceedings of the Third Guelph Symposium on Computer Mediated Communications, University of Guelph, Ontario, Canada.

${ }^{16}$ Mason, R. and Kaye, T. (1989) Mindweave.

${ }^{17}$ Anderson, T. (1989) "The Evolving Role of the Site Coordinator in a Distributed Education Network' in Interaction and Independence Conference papers, O.U. Cambridge, U.K. ed. A. Tait.

${ }^{18}$ Hughes, J. (1989) 'Role Support in Off Campus Student Groups: The University Re-invented?' in Interaction and Independence Conference papers, ed. A. Tait. 